\title{
LOS DERECHOS FUNDAMENTALES COMO MANDATOS DE OPTIMIZACIÓN ${ }^{1}$
}

\author{
Gloria Patricia Lopera Mesa \\ Universidad Eafit, Medellín (Colombia)
}

\begin{abstract}
RESUMEN. En este trabajo se pretende examinar el significado y algunas de las implicaciones que se siguen de entender los derechos fundamentales como mandatos de optimización en el sentido propuesto por Alexy. Para ello se examina, en primer lugar, la caracterización de los principios como mandatos de optimización desarrollada por este autor para, a continuación, analizar algunas de de las objeciones formuladas contra este planteamiento. Finalmente se presentan las razones que permiten sostener que el concepto de mandato de optimización en la teoría de Alexy cobra sentido si se entiende como una convención interpretativa aplicable en los llamados "casos difíciles”, más que como una propiedad derivada ya sea de la estructura abierta de las normas o del carácter gradual de su aplicación”.
\end{abstract}

\begin{abstract}
In this paper the aim is to examine the meaning and some of the implications which result from understanding fundamental rights as optimization commands in the sense put forward by Alexy. In order to do so, we first examine the characterization of principles as optimization commands developed by this author to then go on to analyse some of the objections raised against this approach. Finally, we present the reasons which allow one to hold that the concept of optimization command in Alexy's theory makes sense if it is understood as an interpretative convention, applicable in "hard cases", more than as a characteristic, derived either from the open structure of the norms or from the gradual nature of its application.
\end{abstract}

\footnotetext{
${ }^{1}$ Este trabajo forma parte de una investigación más amplia sobre el tema "Principio de proporcionalidad y ley penal. Bases para un modelo de control de constitucionalidad de las leyes penales”, realizada bajo el auspicio de la Agencia Española de Cooperación Internacional y de la Universidad Eafit, presentada como tesis doctoral en la Facultad de Ciencias Jurídicas y Sociales de Toledo, Universidad de Castilla-La Mancha, en mayo de 2005. Una versión preliminar del mismo fue presentada en el seminario "La aplicación del derecho en los sistemas jurídicos constitucionalizados” realizado en la Universidad Eafit los días 3 a 5 de septiembre de 2003 y cuyas ponencias fueron publicadas en el número 16 de la serie Cuadernos de Investigación, Universidad Eafit, Medellín, 2004. Una versión posterior fue revisada y discutida con los profesores Ángeles Ródenas y Luis Prieto, a quienes agradezco sus valiosas observaciones.
} 


\section{Introducción}

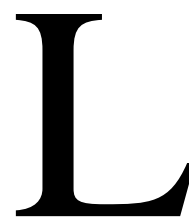

a máxima o principio de proporcionalidad bien puede definirse como un particular desarrollo de la teoría de la argumentación destinado a orientar la aplicación de normas con estructura de principios. Ella ocupa un lugar primordial en una teoría de los derechos fundamentales, concebidos como principios, que en la actualidad goza de importante aceptación en la doctrina y en la práctica de los tribunales constitucionales ${ }^{2}$. Sin duda el autor que ha prestado un mayor impulso a su desarrollo es Robert Alexy quien, en un escrito publicado a finales de los ochenta, ponía de relieve la necesidad de complementar la teoría de los principios con una teoría de la argumentación jurídica de mayor alcance ${ }^{3}$. Parte de su obra posterior, dedicada a ofrecer un esquema de argumentación racional de aplicación de los principios basado en la máxima de proporcionalidad, constituye un importante esfuerzo teórico dirigido a colmar ese vacío.

En este trabajo pretendo examinar más de cerca la relación entre teoría de los principios y máxima de proporcionalidad a partir del análisis del concepto de mandato de optimización. El examen de dicha relación es necesario para contribuir a dilucidar una cuestión que posee no sólo importancia teórica sino también relevancia práctica: determinar si la estructura argumentativa en que consiste la máxima de proporcionalidad puede o no ser utilizada por los tribunales para controlar, y justificar, las intervenciones en derechos fundamentales que llevan a cabo los poderes públicos. Este problema surge cuando se consideran dos tesis parcialmente contrapuestas que han sido formuladas en la teoría del derecho: por un lado, la que afirma la existencia de una relación necesaria entre la aplicación de la máxima de

\footnotetext{
${ }^{2}$ Desarrollada principalmente por Robert Alexy, Teoría de los Derechos Fundamentales (1986), trad. E. Garzón Valdés, Madrid, Centro de Estudios Políticos y Constitucionales, 2001 (2 . reimp.); Martin Borowski, Grundrechte als Prinzipien, Baden-Baden, Nomos, 1998; del mismo autor, "La restricción de los derechos fundamentales", trad. R. Arango, Revista Española de Derecho Constitucional, 59, 2000, págs. 29-56; La estructura de los Derechos Fundamentales, trad. C. Bernal, Santafé de Bogotá, Universidad Externado de Colombia, 2003. En la doctrina española tal concepción es asumida por autores como Luis Prieto, Estudios sobre Derechos Fundamentales, Madrid, Debate, 1990; "La limitación de los Derechos Fundamentales y la norma de clausura del sistema de libertades”, Derechos y Libertades, 8, 2000, págs. 429468; "El constitucionalismo de los derechos", Revista Española de Derecho Constitucional, 71, 2004, págs. 47-72; Manuel Medina Guerrero, La vinculación negativa del legislador a los Derechos Fundamentales, Madrid, McGraw-Hill, 1996. Para un amplio estudio sobre el tema remito al reciente trabajo de Carlos Bernal Pulido, Principio de proporcionalidad y derechos fundamentales, Madrid, Centro de Estudios Políticos y Constitucionales, 2003.

${ }^{3}$ Vid. Robert Alexy, “Sistemas jurídicos, principios jurídicos y razón práctica”, trad. M. Atienza, Doxa, 5, 1988, págs. 139-151, aquí págs. 147 y s.
} 
proporcionalidad y la consideración de (todos) los principios como mandatos de optimización; por otro lado, la que niega que los derechos fundamentales puedan ser concebidos como mandatos de optimización. De admitirse esta última tesis sería forzoso concluir que la máxima de proporcionalidad no podría ser utilizada para resolver conflictos jurídicos en los que se vean involucrados derechos fundamentales, entre ellos, por ejemplo, los que se originan en el control de constitucionalidad de las leyes penales (admitido que estas representan una forma de intervención en tales derechos).

Para responder a esta cuestión avanzaré conforme al siguiente itinerario: como punto de partida, expondré la tesis de la vinculación necesaria entre principios y máxima de proporcionalidad tal y como ha sido formulada por Alexy. Posteriormente examinaré la caracterización de los principios como mandatos de optimización desarrollada por este autor para, a continuación, analizar algunas de las objeciones formuladas contra la idea alexiana de mandato de optimización y la réplica del profesor de Kiel a cada una de ellas. Seguidamente presentaré las razones que permiten sostener que el concepto de mandato de optimización en la teoría de Alexy cobra sentido si se entiende como una convención interpretativa, más que como una propiedad derivada ya sea de la estructura abierta de las normas o de que las mismas sean susceptibles de cumplimiento gradual o aproximativo, pues también normas que imponen una conducta que sólo puede ser realizada o no pueden ser concebidas como mandatos de optimización. Finalmente, pondré de relieve la contradicción que emerge entre dos criterios de precedencia prima facie presentes en el planteamiento de Alexy: por un lado el que otorga prioridad a los derechos individuales sobre los bienes colectivos y, por otro, el que establece el carácter prima facie más fuerte de las determinaciones legislativas que asumen la forma de reglas respecto a los principios, para luego concluir con algunas tesis con las que pretendo dar respuesta al interrogante que motiva este trabajo.

\section{La tesis de la vinculación conceptual necesaria entre principios y máxima de proporcionalidad}

Una de las claves del planteamiento de Alexy es la tesis de la vinculación necesaria entre los principios, entendidos como mandatos de optimización, y el juicio de proporcionalidad: "El carácter de principio implica la máxima de la proporcionalidad, y ésta implica aquella”4. Ello significa que la máxima de proporcionalidad, con sus tres máximas parciales -adecuación, necesidad y proporcionalidad en sentido estricto o ponderación- se infiere

\footnotetext{
${ }^{4}$ Robert Alexy, Teoría de los Derechos Fundamentales, citado, pág. 111.
} 
lógicamente del carácter de principio, pero a su vez que aquellos definen lo que debe entenderse por "optimización"5: así, los subprincipios de adecuación y necesidad se derivan del carácter de los principios como mandatos de optimización con relación a las posibilidades fácticas, mientras que el de proporcionalidad en sentido estricto orienta la optimización con relación a las posibilidades jurídicas.

Para ver con mayor claridad esta implicación, examinemos cómo funciona la máxima de proporcionalidad cuando se trata de optimizar dos principios que entran en colisión como resultado de una intervención legislativa $\left(\mathrm{M}_{1}\right)$ que, con el fin de proteger un derecho fundamental o un bien colectivo expresado en el principio $P_{1}$ impone una restricción al derecho fundamental contenido en el principio $\mathrm{P}_{2}$. A través del examen de adecuación se lleva a cabo una selección de los medios idóneos para satisfacer $\mathrm{P}_{1}$, lo que constituye el primer paso necesario para establecer lo que ordena tal principio con relación a las posibilidades fácticas. El juicio de adecuación se orienta, por tanto, a determinar si, en el supuesto que se examina, $\mathrm{M}_{1}$ constituye un medio idóneo para satisfacer $\mathrm{P}_{1}$.

El segundo paso consiste en el examen de necesidad, donde se verifica que entre diversos medios igualmente idóneos $\left(\mathrm{M}_{1}-\mathrm{M}_{2}\right)$ para satisfacer $\mathrm{P}_{1}$ sea escogido el que resulte más benigno con relación $\mathrm{P}_{2}{ }^{6}$. Consideremos dos supuestos:

1) Si tanto $M_{1}$ como $M_{2}$ resultan igualmente idóneos con relación a $P_{1}\left(P_{1}: M_{1}\right.$ $=\mathrm{M}_{2}$ ), pero $\mathrm{M}_{2}$ afecta menos intensamente que $\mathrm{M}_{1}$ al principio $\mathrm{P}_{2} \mathrm{O}$, dicho de otro modo, $P_{2}$ puede ser realizado en mayor medida si se elige $M_{2}$ y no $M_{1}\left(P_{2}: M_{1}<\right.$ $\mathrm{M}_{2}$ ), entonces desde el punto de vista de la optimización de ambos principios con respecto a las posibilidades fácticas sólo $\mathrm{M}_{2}$ está permitido y $\mathrm{M}_{1}$ está prohibido.

2) Pero si, además de ser igualmente idóneos para satisfacer $P_{1}$, desde la perspectiva de $P_{2}$, tanto $M_{1}$ como $M_{2}$ resultaran ser igualmente restrictivos $\left(P_{2}: M_{1}=M_{2}\right)$, entonces ambos medios estarían permitidos, lo que en este caso llevaría a considerar que la opción legislativa a favor de $\mathrm{M}_{1}$ representa una adecuada optimización de los principios en juego con relación a las posibilidades fácticas.

A su vez, el juicio de proporcionalidad en sentido estricto expresa lo que significa la optimización en relación con las posibilidades jurídicas,

\footnotetext{
${ }^{5}$ Vid. Robert Alexy, “Epílogo a la Teoría de los Derechos Fundamentales”, trad. C. Bernal Pulido, Revista Española de Derecho Constitucional, 66, 2002, págs. 13-64, aquí pág. 26.

${ }^{6}$ El criterio regulativo de la optimización respecto a las posibilidades fácticas responde al llamado óptimo de Pareto. Conforme a dicho criterio un estado de cosas se considera óptimo cuando existe un equilibrio más allá del cual no es posible mejorar la posición de al menos un individuo sin que ello implique desmejorar la situación de algún otro. Sobre este criterio, vid. Juan Carlos Bayón, “Justicia y eficiencia”, en Estado, justicia, derechos, Madrid, Alianza, 2002, págs. 243-277, aquí pág. 247.
} 
es decir, respecto a los principios que juegan en sentido contrario. Aquí el criterio lo suministra la ley de la ponderación, según la cual: “cuanto mayor es el grado de la no satisfacción o afectación de uno de los principios, tanto mayor debe ser la importancia de la satisfacción del otro"”. De él se sigue que la ponderación, aplicada a nuestro ejemplo, puede dividirse en tres pasos que consisten en: 1) definir el grado de la no satisfacción o afectación de $\left.\mathrm{P}_{2} ; 2\right)$ definir la importancia de la satisfacción del principio contrario $\left(\mathrm{P}_{1}\right)$; 3) definir si la importancia de la satisfacción de $\mathrm{P}_{1}$ justifica la afectación o no satisfacción de $\mathrm{P}_{2}{ }^{8}$. Los resultados de esta ponderación se expresan mediante una regla cuya estructura responde a la llamada ley de la colisión que establece lo siguiente: "las condiciones bajo las cuales un principio precede a otro constituyen el supuesto de hecho de una regla que expresa la consecuencia jurídica del principio precedente" ${ }^{\text {. }}$

En trabajos recientes, Alexy ha desarrollado una formulación mucho más precisa de esa suerte de "teoría de la argumentación específica” en la que consiste el principio de proporcionalidad ${ }^{10}$. Sin embargo, a los efectos de este trabajo la formulación esquemática que acabo de presentar resulta suficiente para comprender la estrecha vinculación entre proporcionalidad y principios, que lleva al autor alemán a afirmar que "quien rechace la teoría de los principios (concebidos como mandatos de optimización) debe rechazar también el principio de proporcionalidad”, y a considerar, en consecuencia, que "la disputa sobre la teoría de los principios puede ser vista como un reflejo de la disputa sobre el principio de proporcionalidad”"11.

Llegados a este punto es preciso examinar con mayor detenimiento el significado del concepto de mandato de optimización en la teoría de Alexy.

\section{Los principios como "mandatos de optimización”}

A juicio del profesor de Kiel, la propiedad fundamental que distingue principios y reglas es que los primeros representan mandatos de optimización, es decir, son "normas que ordenan que algo sea realizado en la mayor

\footnotetext{
${ }^{7}$ De tal modo que puede afirmarse que "el subprincipio de proporcionalidad en sentido estricto...es idéntico a la ley de ponderación”. Robert Alexy, “Epílogo a la Teoría de los Derechos Fundamentales”, citado, pág. 31.

${ }^{8}$ Ibíd., pág. 32.

${ }^{9}$ Robert Alexy, Teoría de los Derechos Fundamentales, citado, pág. 94.

${ }^{10}$ Vid. Robert Alexy, “Epílogo a la Teoría de los Derechos Fundamentales”, citado, págs. 13-64; "Die Gewichtsformel”, en Gedächtnisschrift für Jürgen Sonnenschein, Berlín, W. De Gruyter, 2003, págs. 771-792.

${ }^{11}$ Robert Alexy, “On the Structure of Legal Principles”, Ratio Juris, Vol. 13, No. 3, 2000, págs. 294-304, aquí pág. 297. (Paréntesis fuera del texto original).
} 
medida posible, dentro de las posibilidades jurídicas y reales existentes”"12, a diferencia de las reglas, que "contienen determinaciones en el ámbito de lo fáctica y jurídicamente posible"13. Sobre el criterio de la optimización se asienta entonces la tesis fuerte de la separación entre principios y reglas, una separación cualitativa y no gradual que lleva a Alexy a sostener que "toda norma es o bien una regla o un principio"14.

Se ha dicho con razón que la teoría de Alexy constituye una reelaboración teóricamente más profunda y consistente del planteamiento de Dworkin en torno a la distinción entre principios y reglas ${ }^{15}$. En particular, el autor alemán acoge como punto de partida de su teoría la metáfora dworkiniana de la "dimensión de peso" de los principios para construir sobre ella su concepción de los principios como mandatos de de optimización. Concepción que, como ha señalado Alfonso García ${ }^{16}$, comporta cuatro características fundamentales:

Graduabilidad: Los principios ordenan que algo se realice "en la mayor medida posible". Esto sugiere la posibilidad de un mayor o menor grado de satisfacción del principio dentro de los márgenes que determinan ciertas posibilidades jurídicas y fácticas. Por el contrario, las reglas no admitirían gradación alguna en su cumplimiento, en tanto determinan una medida exacta de satisfacción ${ }^{17}$.

Optimización: Afirmar que el cumplimiento de los principios debe tener lugar "en la mayor medida posible”, implica que para establecer si el

12 Robert Alexy, Teoría de los Derechos Fundamentales, citado, pág. 86. La elaboración inicial de esta idea puede verse en su trabajo “Zum Begriff des Rechtsprinzips”, Rechstheorie, cuaderno 1, 1979, págs. 59-87, publicado posteriormente en la compilación Recht, Vernunft, Diskurs, Frankfurt am Main, Suhrkamp, 1995, págs. 177-212 (en adelante cito por esta última).

${ }^{13}$ Robert Alexy, Teoría de los Derechos Fundamentales, citado, pág. 87.

${ }^{14}$ Ibíd., pág. 87.

${ }^{15}$ Juan Ruiz Manero, Jurisdicción y normas, Madrid, Centro de Estudios Constitucionales, 1990, pág. 159. Alfonso García Figueroa, Principios y positivismo jurídico, Madrid, Centro de Estudios Políticos y Constitucionales, 1998, pág. 185.

${ }^{16}$ Alfonso García Figueroa, Principios y positivismo jurídico, citado, págs. 186 y s.

${ }^{17}$ Este comportamiento de las reglas, puntualiza Alexy, no depende de que la acción ordenada en la regla sólo pueda o no ser realizada, como sucede en el caso de la norma de tránsito que impone adelantar sólo por la izquierda, pues también las acciones que admiten ser realizadas en diferente grado pueden ser normadas a través de reglas, siempre que en ellas se ordene con carácter general un determinado grado de cumplimiento, ni más ni menos, como ocurre con las reglas sobre el comportamiento negligente o culposo, en las que según el caso se exige un determinado grado de atención. Vid. Teoría de los Derechos Fundamentales, citado, pág. 87 , nota 25 . Lo que el autor alemán no aclara es si, a su vez, aquellas conductas que por su naturaleza sólo admiten ser cumplidas o no (p. ej. respetar la vida ajena) pueden ser normadas mediante principios. Sobre esto volveremos luego (vid. infra. 5.1). 
principio ha sido cumplido en cada caso no basta con acreditar un grado de satisfacción cualquiera, sino el más alto posible en razón de las circunstancias fácticas y jurídicas ${ }^{18}$.

Deber ser ideal: El mandato de optimización que incorporan los principios cobra sentido desde la perspectiva de un "deber ser ideal” (ideales Sollen) que marca el horizonte normativo al que debe tender su aplicación, pero en cuya formulación aún no han sido consideradas las circunstancias fácticas (posibilidades reales) y jurídicas (presencia de otras normas en colisión) que condicionan su aplicación. Precisamente en no incorporar dichas condiciones radica su connotación de deber ser “ideal”. Así, en uno de sus primeros trabajos sobre el tema de los principios señala Alexy que en lugar de mandatos de optimización, podría hablarse también de “deber ser ideal” (ideales Sollen) entendido, en un sentido general y débil, como "todo deber que no presupone que lo debido sea posible jurídica y fácticamente en su totalidad, y por ello exige sólo un cumplimiento aproximativo o en la mayor medida posible"19. Por el contrario las reglas, al establecer determinaciones referidas a las posibilidades jurídicas y fácticas, serían portadoras de un “deber ser definitivo o real”. Esta propiedad de los principios permitiría explicar el carácter prima facie de los mandatos que imponen al igual que su peculiar comportamiento en caso de colisión.

Carácter prima facie: El mandato que incorporan los principios no es definitivo sino sólo prima facie $^{20}$. Sólo alcanzan a ser mandatos definitivos una vez que, consideradas todas las circunstancias, se establece la medida ordenada de su satisfacción en cada caso, mediante la aplicación de la

${ }^{18}$ Vid. Robert Alexy, Teoría de los Derechos Fundamentales, citado, pág. 91 (nota 37).

${ }^{19}$ Vid. Robert Alexy, “Zum Begriff des Rechtsprinzips”, citado, pág. 204. El significado que propone Alexy se aproxima al sentido en que tal concepto es utilizado por autores como Moore, von Wright o Scheler. Sin embargo, ya en este trabajo nuestro autor advierte acerca de los problemas asociados al concepto de "deber ser ideal” (idealles Sollen), que en escritos posteriores prefiere utilizar con cautela "a causa de los malentendidos a los que puede dar lugar", vid. Teoría de los Derechos Fundamentales, citado, pág. 133, nota 148. Con todo, en trabajos más recientes vuelve a emplearlo en la caracterización de los principios como un "deber ser ideal” que constituye el objeto de la ponderación. “On the Structure of Legal Principles”, citado, pág. 300. Sieckmann, en cambio, se inclina decididamente por considerar que es la cualidad de “deber ser ideal”, más que la de consistir en "mandatos de optimización”, la que realmente constituye la propiedad definitoria de los principios. Vid. Jan-Reinard Sieckmann, Regelmodelle und Prinzipienmodelle des Rechtssystems, Baden-Baden, Nomos, 1990, pág. 75.

${ }^{20}$ El concepto de obligación prima facie es introducido por William David Ross para dar cuenta de los conflictos de deberes morales (Lo correcto y lo bueno (1930), trad. L. Rodríguez, Salamanca, Sígueme, 1994, págs. 43 y ss). Pese a ser criticado por su ambigüedad y confusión, en la actualidad sigue siendo ampliamente utilizado por los teóricos del derecho, aunque en un sentido no del todo coincidente con su formulación inicial y más bien cercano a la reformulación propuesta por John Searle ("Prima Facie Obligations”, en Practical Reasoning, J. Raz (ed.), Oxford, Oxford University Press, 1978, págs. 81-90). 
máxima de proporcionalidad. No obstante, la cualidad prima facie no es exclusiva de los principios, pues también las reglas pueden llegar a perder de su carácter definitivo y adoptar un carácter prima facie, si bien diferente al de los principios, pues el de aquellas tendría una mayor fuerza derivada, no sólo del principio sustancial que fundamenta la regla, sino del respaldo que les confiere el principio formal que ordena seguir las determinaciones normativas impuestas por una autoridad legítima ${ }^{21}$.

El examen de algunas críticas formuladas a esta concepción de los principios servirá para analizar con mayor detenimiento algunas de sus características $^{22}$.

\section{Dos objeciones contra el concepto de "mandato de optimización"}

\section{1. ¿Mandatos de optimización u objetos de un mandato de optimización?}

Una de las críticas dirigidas contra el planteamiento de Alexy pone de relieve la ambigüedad que presenta el propio concepto de mandato de optimización pues no queda claro si el principio es él mismo un mandato de optimización (de la validez o aplicabilidad de una norma) o más bien el objeto de un mandato de optimización ${ }^{23}$. Para ilustrar dicha ambigüedad, Sieckmann señala cómo la norma que establece que la protección del derecho penal debe ser efectiva tanto como sea posible es susceptible de dos interpretaciones:

N1: "La protección del derecho penal debe ser efectiva".

N2: "La protección del derecho penal debe ser efectiva en la medida en que sea fáctica y jurídicamente posible”.

En este ejemplo, N2 sería un mandato de optimización, mientras que N1 sería el objeto de un mandato de optimización ${ }^{24}$. Visto con detenimiento, la

${ }^{21}$ Vid. Robert Alexy, Teoría de los Derechos Fundamentales, citado, págs. 98 y ss. El papel de los principios formales en el razonamiento jurídico es analizado con mayor detenimiento por este autor en su "Epílogo a la Teoría de los Derechos Fundamentales”, citado, pág. 49 y ss. Para un estudio más amplio y detallado vid. Marius Raabe, Grundrechte und Erkenntnis. Der Einschätzungsspielraum des Gesetzgebers, Baden-Baden, Nomos, 1998; Virgilio Afonso da Silva, Grundrechte und gesetzgeberische Spielräume, Baden-Baden, Nomos, 2002.

${ }^{22}$ Aquí sólo nos detendremos en dos de las objeciones formuladas contra el planteamiento de Alexy. Para el examen crítico de otras objeciones vid. Robert Alexy, "Zur Struktur der Rechtsprinzipien”, en Regeln, Prinzipien und Elemente im System des Rechts, B. Schilcher / P. Koller / B. C. Funk (Hg.), Wien, Verlag Österreich, 2000, págs. 31-52; “Epílogo a la Teoría de los Derechos Fundamentales”, citado, págs. 14 y ss; Martin Borowski, "Prinzipien als Grundrechtsnormen”, Zeitschrift für öffentliches Recht, 53, 1998, págs. 307-335.

${ }^{23}$ Vid. Jan-Reinard Sieckmann, Regelmodelle und Prinzipienmodelle..., citado, págs. 63 y ss. Un acertado desarrollo de este argumento en Alfonso García Figueroa, Principios y positivismo jurídico, citado, págs. 187 y ss.

${ }^{24}$ Jan-Reinard Sieckmann, Regelmodelle und Prinzipienmodelle..., citado, pág. 64. 
definición de los principios como mandatos de optimización envuelve una paradoja ya que, como ha señalado Aarnio, un mandato de optimización es en cualquier caso una regla: "Un mandato, de acuerdo con el concepto, es como una regla: o se sigue o no se sigue. De este modo, el mandato de optimización es también una regla que no puede ser aplicada "más o menos”. Se optimiza o no se optimiza. Por ejemplo, en caso de conflicto entre dos principios valorativos, los principios deben ser armonizados de manera óptima y sólo de esta manera.”25

Alexy responde a esta crítica pero minimiza su alcance advirtiendo que en todo caso ella no obliga a abandonar la tesis de la optimización, sino más bien a introducir una distinción entre mandatos a ser optimizados (commands to be optimized) y mandatos de optimización (commands to optimize). Los primeros, puntualiza Alexy, "son los objetos que intervienen en la ponderación y pueden ser calificados como deber ser ideal. Un deber ser ideal es algo que ha de ser optimizado y, de este modo, transformado en un deber ser real. En tanto objetos de optimización, están situados en el nivel de los objetos (object nivel)". Por el contrario, "los mandatos de optimización están situados en un meta nivel. Desde allí prescriben lo que ha de hacerse con aquello que se encuentra en el nivel de los objetos (object nivel). Ellos imponen la obligación de que su objeto, el mandato a ser optimizado (command to be optimized), sea realizado en la mayor medida posible. En tanto mandatos de optimización no han de ser optimizados, sino satisfechos con una optimización (fulfilled by optimization)”26.

Los principios, admite Alexy, “en tanto son materia de ponderación no consisten en mandatos de optimización sino más bien en mandatos a ser optimizados. Como tal, ellos comprenden un “deber ser ideal” que todavía no ha sido relativizado según las posibilidades jurídicas y fácticas” ${ }^{27}$. Sin embargo no encuentra problemático continuar refiriéndose a ellos como mandatos de optimización pues dicha expresión, además de estar más arraigada en el lenguaje de los juristas, expresa de manera más sencilla la naturaleza de los principios. Esto obedece a que "existe una conexión necesaria entre el “deber ser ideal”, esto es, el principio como tal, y el mandato de optimización como una regla. El “deber ser ideal” implica el mandato de optimización y viceversa”. De modo que, concluye el profesor de Kiel,

${ }^{25}$ Aulis Aarnio, “Las reglas en serio”, en La normatividad del derecho, A. Aarnio, E. Garzón Valdés, J. Uusitalo (comps.), trad. S. Urbina, Barcelona, Gedisa, 1997, págs. 17-35, aquí pág. 27.

${ }^{26}$ Robert Alexy, “On the Structure of Legal Principles”, citado, pág. 300. Para una versión más amplia de este trabajo vid. “Zur Struktur der Rechtsprinzipien”, citado, págs. 38 y s.

${ }^{27}$ Robert Alexy, “On the Structure of Legal Principles”, citado, pág. 300. 
"es aconsejable, por razones de simplicidad, designar los principios como mandatos de optimización y emplear distinciones más precisas sólo donde estas resulten necesarias" ${ }^{28}$.

Sin embargo, la precisión que introduce Alexy con ocasión de esta crítica no resulta en modo alguno innecesaria, pues ayuda a clarificar el significado de un concepto cuya ambigüedad, por cierto, está en la base de la objeción que se examina a continuación.

\subsection{No todos los principios son mandatos de optimización}

Manuel Atienza y Juan Ruiz Manero han cuestionado que la cualidad de mandatos de optimización sea predicable de todos los principios, ya que sólo es adecuada para dar cuenta de una clase de principios, las llamadas directrices o normas programáticas, razón por la cual, a juicio de estos autores, la teoría de Alexy resulta "distorsionadora" ${ }^{29}$. Examinemos las razones en que se apoya dicha objeción:

\subsubsection{La distinción entre principios en sentido estricto y directrices}

El núcleo de la teoría desarrollada por Atienza y Ruiz Manero consiste en la doble distinción que proponen entre reglas y principios, por un lado, y al interior de esta última categoría, entre principios en sentido estricto y directrices o normas programáticas ${ }^{30}$. A continuación me ocuparé de la segunda de estas diferencias desde dos de los enfoques bajo los cuales es contemplada por estos autores:

Desde un enfoque estructural, el punto de partida es la consideración de que todas las normas responden a una estructura condicional del tipo " $\mathrm{Si}$ A, entonces B", donde A representa el antecedente o condición de aplicación, consistente en la descripción de un caso genérico, y B el consecuente o consecuencia jurídica, que expresa la calificación deóntica ya sea de una conducta o de un estado de cosas. Sobre esta base, principios en sentido estricto y directrices se asemejan en que ambos formulan de modo abierto su condición de aplicación ${ }^{31}$, pero mientras los principios en sentido estricto

\footnotetext{
${ }^{28}$ Ibíd., pág. 301.

${ }^{29}$ Manuel Atienza y Juan Ruiz Manero, Las piezas del Derecho. Teoría de los enunciados jurídicos, Barcelona, Ariel, 1996, pág. 11.

${ }^{30}$ Ibíd., págs. 6 y ss.

${ }^{31}$ Acogiendo una sugerencia formulada por Josep Aguiló, en trabajos posteriores estos autores caracterizan los principios (tanto en sentido estricto como directrices) como normas categóricas en el sentido propuesto por von Wright, esto es, como normas cuya condición de aplicación no contiene otra cosa sino la propiedad de que haya una oportunidad de realizar la conducta prescrita en el consecuente. Vid. Manuel Atienza y Juan Ruiz Manero, "Rules and Principles Revisited”, Associations, 4, 2000, págs. 147-156, aquí págs. 150 y s; Ilícitos atípicos.
} 
presentan de manera cerrada el modelo de conducta prescrito (consecuente), las directrices lo configuran de manera abierta ${ }^{32}$. A juicio de Atienza y Ruiz Manero, tal diferencia estructural determina que los primeros, una vez comprobado que desplazan a otros principios en un balance de razones, exijan un cumplimiento pleno, mientras que las directrices prescriben el cumplimiento de un estado de cosas en la mayor medida posible ${ }^{33}$.

Para ilustrar su posición, los autores presentan la norma expresada en el artículo 14 C.E. como ejemplo de un principio en sentido estricto. Dicho enunciado establece la prohibición de discriminar a los españoles por motivos de nacimiento, raza, sexo, opinión o cualquier otra condición o circunstancia personal o social. Ahora bien, esta norma no suministra mayor información sobre las condiciones en que procede su aplicación. No sucede igual, a juicio de los profesores de Alicante, con la descripción de la conducta prohibida: discriminar, cuya formulación cerrada permite exigir un cumplimiento pleno: o se cumple o no se cumple, para el caso, o se discrimina o no se discrimina, pero no caben modalidades graduales de cumplimiento. Por su parte proponen como ejemplo de directriz el artículo 51.1. C.E, donde se establece que "los poderes públicos garantizarán la defensa de los consumidores y usuarios, protegiendo, mediante procedimientos eficaces, la seguridad, la salud y los legítimos intereses económicos de los mismos". Como sucede con el principio de igualdad, también en este caso las condiciones de aplicación están configuradas de manera abierta, pues no queda claro en qué casos, bajo qué condiciones deben los poderes públicos proteger a los consumidores y usuarios. Sin embargo, a diferencia del ejemplo anterior, la norma del artículo 51.1. ni ordena ni prohíbe ninguna acción en particular, sino sólo la consecución de un cierto estado de cosas en el cual la seguridad, la salud y los legítimos intereses económicos de consumidores y usuarios se encuentren protegidos: "cuáles sean las acciones (o los cursos de acción) causalmente idóneas para lograr este objetivo no se encuentra constitucionalmente determinado.”34

Este diferente comportamiento de ambos tipos de normas guarda relación con el paralelismo que los autores establecen entre la distinción entre reglas de acción y reglas de fin y la caracterización de los principios en sentido estricto y las directrices. Mientras las reglas de acción prescriben la realización de una acción concreta, las reglas de fin prescriben la obtención

Sobre el abuso del derecho, el fraude a la ley y la desviación de poder, Madrid, Trotta, 2000, págs. 18 y s. Según la definición de von Wright, una norma es categórica "si su condición de aplicación es la condición que tiene que cumplirse para que exista una oportunidad de hacer aquello que constituye su contenido, y ninguna otra condición”. Georg Henrik von Wright, Norma y acción. Una investigación lógica, trad. P. García Ferrero, Madrid, Tecnos, 1970, pág. 91.

32 Por su parte las reglas, según el enfoque estructural de Atienza y Ruiz Manero, se caracterizan por configurar de modo cerrado tanto el antecedente como el consecuente.

${ }^{33}$ Manuel Atienza y Juan Ruiz Manero, Las piezas del Derecho, citado, pág. 7.

${ }^{34}$ Ibíd., págs. 10 y s. 
de un estado de cosas; ahora bien, la misma distinción se reproduce en el caso de los principios en sentido estricto (prescriben acciones) y las directrices (prescriben alcanzar estados de cosas), con la única diferencia de que mientras las reglas (de acción y de fin) configuran el caso de forma cerrada, principios y directrices no especifican su condición de aplicación ${ }^{35}$. Así pues, la proximidad entre las directrices y las reglas de fin (ambas prescriben estados de cosas y no acciones), sumado al hecho de que las primeras dejarían necesariamente en manos de los destinatarios la elección de los medios idóneos para cumplir con el fin prescrito (dado el carácter abierto de su consecuente), darían cuenta de la aplicabilidad gradual y optimizable de las directrices, cosa que no sucedería en el caso de los principios en sentido estricto, pues estos, una vez determinado que hay lugar a aplicarlos, por razones lógicas exigirían un cumplimiento pleno, consistente en la realización de la acción prescrita.

El segundo de los enfoques propuestos por Atienza y Ruiz Manero para contemplar la distinción aludida es el que llaman funcional, o la perspectiva de razones para la acción, bajo el cual los principios en sentido estricto se conciben como razones de corrección fundadas en valores, de carácter último y que, por tanto, no admiten ser desplazadas por razones de otro tipo (utilitario) sino sólo por otras razones de corrección igualmente basadas en principios. Por su parte, las directrices generan razones para la acción de tipo utilitario, que bien pueden ser superadas ya sea por otras razones del mismo tipo o por razones de corrección fundadas en principios. Así pues, las razones de corrección resultan prioritarias respecto a las razones de utilidad o, dicho de otro modo, los principios en sentido estricto “pesan más” que las directrices ${ }^{36}$.

\footnotetext{
${ }^{35}$ Ibíd., págs. 7 y ss. A juicio de estos autores, la distinción entre normas que prescriben acciones y normas que prescriben alcanzar estados de cosas cobra relevancia en tanto estas últimas dejan en manos de los destinatarios la selección de los medios causalmente idóneos para alcanzar el estado de cosas prescrito, permitiendo a aquellos un margen de discreción que no existe en el caso de las reglas de acción. No obstante, Moreso ha señalado acertadamente que, en definitiva, todas las normas pueden verse como normas de fin, en la medida en que también las normas que ordenan realizar una acción (del tipo “presentarse mañana a la oficina”) admitirían diversas modalidades de cumplimiento ("se puede ir en tren, autobús, bicicleta o andando”), con lo cual estas últimas también concederían a los destinatarios cierto margen de discreción para elegir el modo de cumplir con la acción prescrita. Vid. José Juan Moreso, “El encaje de las piezas del derecho (I)”, Isonomía, 14, 2001, págs. citado, págs. 135-157, aquí pág. 150 y s. Siendo así, nada obsta para que, desde esta perspectiva, también los principios en sentido estricto concedan al destinatario un margen para la elección de medios para cumplir la acción prescrita, lo que sin duda contribuye a debilitar la distinción entre estos y las directrices.

${ }^{36}$ Atienza y Ruiz Manero también examinan la citada distinción desde un tercer enfoque, cuyas conclusiones se asemejan a las derivadas del enfoque funcional. Se trata de la perspectiva de las relaciones de poder e intereses, bajo el cual la diferencia radica en que las directrices no
} 
En trabajos posteriores, los profesores de Alicante han formulado importantes precisiones a su planteamiento. Por una parte, han vinculado la propiedad "todo o nada” de los principios en sentido estricto ya no sólo a una cualidad estructural (la configuración cerrada de su consecuente) sino también a su carácter de razones de corrección que incorporan valores "últimos”. Atribuir valor último a una acción o estado de cosas significa que no se toman en cuenta sus consecuencias, lo que, para el caso de los principios en sentido estricto, supone que "se puede determinar que una acción está justificada con independencia del proceso causal, esto es, sin considerar sus consecuencias”. En otras palabras, que respecto de ella se emplean "criterios de corrección que implican una exigencia todo o nada, en el sentido de que el juicio de corrección no es graduable: una acción o una decisión es o no correcta”37. Por el contrario, las directrices ordenan la consecución en el mayor grado posible de ciertos estados de cosas que constituyen objetivos colectivos valiosos, aunque no con carácter último. Aquí la relación entre acciones y estados de cosas no es analítica o conceptual, como en el caso de los principios en sentido estricto, sino causal. El criterio de justificación empleado con relación a las directrices ya no es el de "corrección” sino el de “eficiencia”, el cual sí admite ser satisfecho en diversos grados ${ }^{38}$.

La segunda precisión de Atienza y Ruiz Manero supone en buena medida una rectificación de algunas de las tesis sostenidas en Las piezas del Derecho, dirigida a constatar que en el nivel de los principios no existe sólo un razonamiento en términos sustantivos, pues también son relevantes

delimitan ex ante la articulación de los intereses en conflicto ni de las finalidades relativamente incompatibles, esto es, "no determinan los espacios de poder de una vez por todas haciendo abstracción de los intereses realmente en presencia en cada caso..., sino que hacen depender dicha determinación de circunstancias variables y no determinadas a priori, esto es, no contenidas en las normas". Por su parte, los principios en sentido estricto incorporan valores que se consideran "razones categóricas frente a cualesquiera intereses", que prevalecen frente a las directrices y juegan un papel predominantemente negativo: "los principios en sentido estricto no tratan de ordenar la concurrencia de intereses ni de promover unos u otros intereses sociales, sino de evitar que la persecución de cualesquiera intereses pueda dañar a dichos valores”. Ello no obsta para admitir que los ordenamientos liberal-democráticos incorporan una pluralidad de valores potencialmente conflictivos y cuya jerarquía interna no siempre se encuentra determinada, conflictos que han de resolverse mediante la ponderación a fin de establecer cuál de los valores ha de prevalecer en cada caso. Las piezas del Derecho, citado, págs. 17 y s. Así pues, mientras con las directrices se busca ordenar la concurrencia de diversos intereses y objetivos sociales, con los principios en sentido estricto se busca establecer un marco que limite la persecución de dichos intereses.

${ }^{37}$ Manuel Atienza y Juan Ruiz Manero, Ilícitos atípicos..., citado, pág. 21.

${ }^{38}$ Desde el punto de vista de las directrices -sostienen estos autores- "una acción justificada es la que, respetando las otras normas del ordenamiento (y en especial los límites que se derivan de los principios en sentido estricto), es la más eficiente, esto es, facilita la obtención del estado de cosas ordenado con el menor sacrificio de los otros fines”. Ibíd., pág. 22. 
ciertas exigencias, derivadas de la dimensión institucional del derecho, que en ocasiones limitan el logro de los valores y fines sustantivos que el propio derecho trata de realizar. Tal relevancia se aprecia al momento de justificar instituciones jurídicas como los estados de excepción y de sitio, los cuales no plantean, sin más, un conflicto entre principios en sentido estricto, pues es evidente que la suspensión en el presente de ciertos derechos fundamentales al amparo de un estado de excepción o de sitio no guarda una relación analítica o conceptual (propia de los principios en sentido estricto) con la vigencia futura de tales derechos, sino a lo sumo una relación causal (propia de las directrices): "la suspensión, hoy, no es una forma de realización futura, sino un medio, necesario si se quiere en ciertas circunstancias, para asegurar la vigencia futura de esos derechos y libertades”39.

A fin de eludir la conclusión que parece imponerse en este caso -según la cual para justificar instituciones tales como los estados de excepción sería preciso admitir la prevalencia de una directriz (garantizar la vigencia futura del orden jurídico en su conjunto) frente a principios en sentido estricto como los que ordenan respetar derechos fundamentales- y, al mismo tiempo, apuntalar la tesis de la prevalencia incondicionada de principios en sentido estricto sobre directrices, los profesores de Alicante proponen integrar en su esquema una nueva categoría de normas ignorada en sus trabajos anteriores: la de los principios institucionales. Estos acogerían las diversas exigencias derivadas del carácter institucional del derecho, necesarias para garantizar el funcionamiento adecuado de la “maquinaria” jurídica y, con ello, hacer posible que el derecho pueda cumplir con los fines y valores sustantivos que pretende realizar. Pero a la vez, sostienen estos autores, preservar esta dimensión institucional resulta importante pues con ella se imprime carácter regimentado al derecho, necesario para superar los déficits operativos del discurso moral ${ }^{40}$. De modo que, al lado de los tradicionales principios sustantivos, ha de admitirse la existencia de principios institucionales ${ }^{41}$, los cuales, en ocasiones, pueden llegar a derrotar a los primeros y, en definitiva, a matizar la prioridad incondicionada de los derechos fundamentales sobre

\footnotetext{
${ }^{39}$ Manuel Atienza y Juan Ruiz Manero, "La dimensión institucional del Derecho y la justificación jurídica”, Doxa, 24, 2001, págs. 115-130, aquí pág. 122.

${ }^{40}$ Ibíd., págs. 129 y s.

${ }^{41}$ A su vez, al interior de los principios institucionales se reproduce la distinción entre principios en sentido estricto y directrices, con lo cual existirían cuatro categorías: (1) principios sustantivos en sentido estricto, (2) directrices sustantivas, (3) principios institucionales en sentido estricto (ejemplo de estos serían, entre otros, la separación de poderes o el principio de deferencia al legislador democrático), (4) directrices institucionales (referidas al funcionamiento eficaz del sistema jurídico). Con todo, esta clasificación no afectaría la tesis de la prevalencia de los principios sobre las directrices en caso de conflicto. Ibíd., pág. 126.
} 
otros objetivos sociales valiosos, aunque no últimos, pues en qué otra cosa, sino en lo segundo, consiste el interés por preservar la vigencia y la eficiencia del sistema jurídico.

En definitiva, la distinción que Atienza y Ruiz Manero establecen entre principios en sentido estricto y directrices, por lo demás asumida con carácter exhaustivo y excluyente ${ }^{42}$, les permite sostener dos tesis contrarias al planteamiento de Alexy:

1) "que los principios puedan ser cumplidos en diversos grados es verdadero por lo que se refiere a las directrices o normas programáticas, pero no lo es en el caso de los principios en sentido estricto", con lo cual estos últimos no pueden ser concebidos como mandatos de optimización ${ }^{43}$.

2) Todo conflicto entre principios en sentido estricto (sean estos de carácter sustantivo o institucional) y directrices se resuelve, con carácter general, con el triunfo de los primeros.

Vistas así las cosas, la crítica formulada por los profesores de Alicante supondría un serio revés para la concepción alexiana de los principios como mandatos de optimización, pues pondría en entredicho la vinculación necesaria entre principios y máxima de proporcionalidad defendida por este autor como una de las tesis centrales de su teoría de los principios o, por lo menos, obligaría a circunscribir su alcance sólo a la aplicación de las directrices, lo que también socavaría los cimientos de su teoría de los derechos fundamentales. Así pues, es preciso establecer si en realidad el planteamiento del profesor de Kiel se ve afectado por la crítica de Atienza y Ruiz Manero.

\subsubsection{La réplica de Alexy}

En el planteamiento de los profesores de Alicante es posible separar dos cuestiones: En primer lugar, la tesis que sostiene el carácter todo o nada de los principios en sentido estricto y que, por tanto, excluye su consideración como mandatos de optimización. Esta se apoya, básicamente, en la configuración cerrada de su consecuente y en la vinculación de tales principios con razones de corrección que implican una exigencia todo o nada ("una acción o una decisión es o no correcta”). En segundo lugar, la tesis que afirma la prioridad de los principios en sentido estricto sobre las directrices, basada en la prioridad de las razones de corrección sobre las razones de fin. Abordaremos, en este orden, la réplica de Alexy a cada una de estas tesis.

\footnotetext{
${ }^{42}$ Manuel Atienza y Juan Ruiz Manero, Las piezas del Derecho, citado, pág. 5.

${ }^{43}$ Ibíd., pág. 9.
} 


\subsubsection{El carácter "todo o nada” de los principios en sentido estricto}

Para responder a esta cuestión, el autor alemán toma como punto de partida la reconstrucción en términos condicionales del principio formulado en el artículo 14 C.E., propuesta por Atienza y Ruiz Manero como ejemplo de principio en sentido estricto:

"Si (condición de aplicación) un órgano jurídico usa sus poderes normativos (esto es, dicta una norma para regular un caso genérico o la aplica para resolver un caso individual, etc.) y en relación con el caso individual o genérico de que se trate no concurre otro principio que, en relación con el mismo, tenga mayor peso, entonces (solución normativa) a ese órgano le está prohibido discriminar basándose en razones de nacimiento, raza, sexo, opinión o cualquier otra condición o circunstancia personal o social”44.

A juicio de Alexy, la pieza decisiva en esta reconstrucción es la cláusula "y en relación con el caso individual o genérico de que se trate no concurre otro principio que, en relación con el mismo, tenga mayor peso", la cual, por otra parte, no figura expresamente en el texto constitucional. Es la adición de esta cláusula de reserva no escrita, y no la configuración cerrada de su consecuente o su carácter de razón de corrección, lo que convierte a la norma en no susceptible de cumplimiento gradual (nicht graduell erfüllbar ${ }^{45}$. Sin embargo, en opinión de este autor, tal propiedad resulta trivial, porque cualquier principio al que se añada una cláusula de este tipo adquiere con ello el carácter de una norma "todo o nada"46. Por otra parte, dicha propiedad no excluye que la norma en cuestión pueda ser objeto de un mandato de optimización. En tal sentido señala Alexy que "las normas cerradas a través de cláusulas restrictivas de esta clase se asemejan a mandatos de optimización y tienen, por las mismas razones que estos, carácter de reglas”. ${ }^{47}$ Creo que esta última idea se comprende mejor si se tiene en cuenta la distinción entre mandatos de optimización (commands to optimize) y mandatos a ser optimizados (commands to be optimized), examinada anteriormente ${ }^{48}$. La cláusula a la que se hace referencia contiene entonces un mandato de optimización, esto es, una regla situada en un "meta nivel” que prescribe examinar si en cada caso concurre o no un principio que tenga mayor peso, para lo

\footnotetext{
${ }^{44}$ Ibíd, pág. 9 (cursivas fuera del original).

${ }^{45}$ Vid. Robert Alexy, “Zur Struktur der Rechtsprinzipien”, citado, págs. 44 y s.

${ }^{46}$ Vid. Robert Alexy, “Zum Begriff des Rechtsprinzips”, citado, pág. 192.

${ }^{47}$ Robert Alexy, “Zur Struktur der Rechtsprinzipien“, citado, pág. 44.

${ }^{48}$ Vid. supra 4.1.
} 
cual es preciso considerar qué es lo ordenado en ese caso con relación a las posibilidades jurídicas y fácticas ${ }^{49}$.

A juicio de Alexy, la importancia de dicha cláusula en la reconstrucción del artículo 14 C.E. como un principio se advierte al considerar que su ausencia llevaría a interpretar la prohibición de discriminación como una regla estricta y, en consecuencia, a excluir todo trato desigual. Así, tratándose de la prohibición de discriminación por razón de sexo, carecería de justificación cualquier política de discriminación inversa dirigida a promover la igualdad real entre hombres y mujeres, así como la adopción de medidas vinculadas a situaciones como el embarazo o la maternidad. Sin embargo, tal interpretación del artículo 14 C.E. no corresponde al planteamiento de Atienza y Ruiz Manero, en el cual la referencia al “mayor peso" de los principios enfrentados sugiere la necesidad de una ponderación..$^{50}$ No obstante, puntualiza el profesor de Kiel, los objetos que intervienen en una ponderación sólo admiten ser reconstruidos racionalmente como principios, en el sentido de la tesis de la optimización. Considerados como objetos de una ponderación, esto es, como mandatos a optimizar, tales principios serían susceptibles de cumplimiento gradual. La anterior afirmación es válida respecto a todas las normas de derecho fundamental, al contrario de lo que sostienen Atienza y Ruiz Manero. En ese orden de ideas -concluye Alexy- el argumento de estos autores, según el cual algunos principios no admiten cumplimiento gradual y, en tal sentido, tendrían carácter de reglas, no constituye una objeción de peso en contra de la tesis de la optimización ${ }^{51}$.

\subsubsection{La prevalencia de los derechos individuales sobre los bienes colectivos}

En el planteamiento de Atienza y Ruiz Manero la "no graduabilidad” de los principios en sentido estricto se vincula a la consideración de tales principios como "razones de corrección” o “deontológicas”, distintas y prevalentes respecto a las "razones de fin" propias de las directrices u objetivos sociales. Desde esta premisa se plantea el problema de si la consideración de los principios como mandatos de optimización les sitúa en el terreno del utilitarismo y del razonamiento teleológico, y si ello resulta incompatible

\footnotetext{
${ }^{49}$ En otro lugar, al referirse al “doble carácter” (de regla y principio) de las normas iusfundamentales que se construyen mediante la adición de cláusulas de reserva relativas a principios, Alexy advierte cómo este tipo de cláusulas, "no formulan otra cosa que las tres partes del principio de proporcionalidad”. Robert Alexy, Teoría de los Derechos Fundamentales, citado, pág. 137.

${ }^{50}$ Robert Alexy, “Zur Struktur der Rechtsprinzipien”, citado, pág. 45.

${ }^{51}$ Ibíd., pág. 45.
} 
con el carácter deontológico de los derechos fundamentales ${ }^{52}$. Con el fin de sustraer a estos últimos del cálculo utilitario y preservar su carácter de "razones últimas", estos autores defienden una primacía incondicionada de los principios en sentido estricto sobre las directrices, lo que lleva a sostener, en consecuencia, la primacía absoluta de los derechos fundamentales sobre los bienes colectivos. En este punto, el planteamiento de los profesores de Alicante se aproxima a una de las críticas que Habermas dirige en contra de la teoría de los principios de Alexy, según la cual, una vez concebidos como mandatos de optimización, los derechos individuales podrían, cuando las circunstancias así lo exijan, ser sacrificados en aras de objetivos colectivos, perdiendo así su carácter de "triunfos" frente a la mayoría y, con ello, su mayor fuerza justificatoria ${ }^{53}$.

En opinión de Alexy, quienes suscriben tal objeción aciertan al señalar que la interpretación de los derechos como mandatos de optimización no puede excluir el riesgo de su excesiva limitación en beneficio de bienes colectivos. También es cierto que tal peligro podría ser conjurado si se asume una prioridad estricta de los derechos fundamentales frente a todos los bienes colectivos. Sin embargo, esta alternativa comporta igualmente desventajas porque impediría, por ejemplo, establecer limitaciones al derecho de propiedad para garantizar la protección del medio ambiente, restringir la libertad de profesión en aras de la protección de consumidores o limitar la libertad de investigación a fin de impedir ciertos experimentos con animales $^{54}$.

Consciente de estas desventajas, Habermas se muestra dispuesto a reconocer que "ciertamente, en el contexto concreto de fundamentación de la decisión de un caso particular, no todo derecho puede imponerse contra todo bien colectivo, pero solamente no podrá imponerse cuando la primacía de un bien colectivo pueda justificarse a su vez a la luz de principios"55, con lo cual, "en última instancia son sólo derechos los que deben convencernos en el juego argumentativo" ${ }^{56}$. Esta segunda alternativa, consistente en re-

\footnotetext{
${ }^{52}$ Ibíd., pág. 46.

${ }^{53}$ Vid. Jürgen Habermas, Facticidad y Validez (1992), trad. castellana de la 4ª ed. alemana a cargo de M. Jiménez Redondo, Madrid, Trotta, 1998, pág. 332. Un desarrollo ulterior de este argumento se encuentra en "Anhang zu Faktizität und Geltung. Replik auf Beiträge zu einem Symposion der Cardozo Law School“, en Die Einbeziehung des Anderen. Studien zur politischen Theorie, Frankfurt a. M., Suhrkamp, 1996, apéndice que no está incluido en la edición en castellano de esta obra (La inclusión del otro. Estudios de Teoría Política, trad. J. C. Velasco Arroyo y G. Vilar Roca, Barcelona, Paidós, 1999). La otra crítica de Habermas se refiere al carácter irracional de la ponderación, pero ella no será aquí considerada.

${ }^{54}$ Vid. Robert Alexy, "Zur Struktur der Rechtsprinzipien“, citado, págs. 50 y s.

${ }^{55}$ Jürgen Habermas, Facticidad y Validez, citado, pág. 332.

${ }^{56}$ Ibíd., pág. 333.
} 
conducir los bienes colectivos a derechos individuales, puede ser entendida al menos de dos maneras: como una completa disolución de la categoría de los bienes colectivos en la de los derechos individuales, lo que dejaría por fuera a muchos bienes colectivos que, pese a no ser reducibles a ningún derecho individual, bajo ciertas condiciones pueden justificar limitaciones a tales derechos, como es el caso del interés en la conservación del patrimonio histórico. Pero si, por el contrario, sólo se exige que el bien colectivo tenga un grado cualquiera de repercusión positiva sobre algún derecho individual, el ámbito de los bienes susceptibles de justificar restricciones a derechos se amplía de tal modo que el criterio de la "reductibilidad" deviene inadecuado para delimitar el círculo de bienes colectivos aptos para fundamentar la restricción legítima de derechos individuales ${ }^{57}$.

A juicio del profesor de Kiel, también debe excluirse una tercera alternativa, consistente en reducir el catálogo de derechos fundamentales para así evitar muchos supuestos de colisión con bienes colectivos, siguiendo un cuestionable criterio según el cual, "en lugar de tener que limitar, es mejor eliminar"58. Finalmente, Alexy explora una cuarta alternativa de resolver los problemas que plantea la colisión entre derechos individuales y bienes colectivos. En este caso se trataría de considerar las restricciones basadas en bienes colectivos, no como una intervención en el derecho individual, sino más bien como una “configuración” o “regulación” del mismo, solución que para este autor resulta igualmente inaceptable. ${ }^{59}$

Excluidas tales posibilidades sólo queda, en opinión de Alexy, la alternativa de admitir la restricción de derechos individuales en aras de bienes colectivos y delimitar tales restricciones a través del principio de proporcionalidad. Este último presupone la consideración de los derechos fundamentales como principios, esto es, como mandatos de optimización. El riesgo de que tal concepción contribuya a debilitar los derechos fundamentales sólo puede ser prevenido -según el profesor de Kiel- mediante la combinación de tres factores: el primero es, precisamente, la teoría de los principios que, en lugar de debilitar, contribuye a fortalecer los derechos en la medida en que, como lo expresa la ley de la ponderación, la resistencia de los derechos concebidos como principios será tanto más fuerte, cuanto más intensa sea la intervención que se trata de justificar. En segundo lugar, la teoría formal de los principios debe ser complementada con una teoría sustancial de los derechos, en la cual la afirmación de la prevalencia prima facie de los derechos

${ }^{57}$ Vid. Robert Alexy, “Zur Struktur der Rechtsprinzipien“, citado, pág. 51.

${ }^{58}$ Ibíd., pág. 52.

${ }^{59}$ Ibíd., pág. 52; para un desarrollo más amplio de esta idea vid. Teoría de los Derechos Fundamentales, citado, págs. 321 y ss. 
individuales sobre los bienes colectivos desempeña un papel fundamental. Finalmente, es preciso que lo anterior encuentre un respaldo efectivo en la realidad, a lo cual sin duda puede contribuir el desarrollo de una acertada jurisprudencia constitucional, pero que, en definitiva, sólo puede apoyarse en el consenso de los ciudadanos ${ }^{60}$.

\section{Una propuesta de interpretación de la tesis de los principios como mandatos de optimización}

El examen de la tesis de Atienza y Ruiz Manero, que niega a los principios en sentido estricto la propiedad de ser optimizables, y de la réplica formulada por Alexy, permite apreciar las distintas estrategias que en cada caso se emplean para fundamentar el concepto de "mandato de optimización" así como la dificultad para situar ambas argumentaciones en un terreno común. Tal divergencia lleva incluso a dudar que unos y otro se refieran a lo mismo cuando emplean tal concepto. Así, en el caso de Atienza y Ruiz Manero, la idea de mandato de optimización obedece a una característica presente en la estructura lógica de las normas (su consecuente está configurado de modo abierto) y en el tipo de razón para la acción que representan (razones de utilidad no últimas cuyo criterio de justificación es la eficiencia). Por su parte, creo que la caracterización alexiana de los principios como mandatos de optimización tiene poco que ver con las consideraciones anteriores y, más bien, es el resultado de asumir una convención interpretativa que lleva a concebir que estas normas postulan un "deber ser ideal" cualitativamente distinto del "deber ser real” propio de las reglas. A juicio de Sieckmann este distinto "deber ser" se traduce en un distinto modo de validez: "mientras la validez de una regla implica el mandato de su aplicación estricta, esto es, la aplicación en todos los casos en que la misma resulte aplicable, la validez de un principio significa únicamente que este ha de ser satisfecho en la medida más alta posible con relación a las posibilidades jurídicas y fácticas”־1. Así pues, según el planteamiento de Alexy, para atribuir la cualidad de optimizable a una norma no resulta ser determinante ni la posibilidad de cumplimiento gradual de la conducta prescrita ni la configuración abierta del consecuente de la norma en cuestión. Veamos:

\subsection{La "graduabilidad" de los principios}

Para entender en qué sentido pueden caracterizarse como "mandatos de optimización" incluso aquellos principios que prescriben una conducta cuya

\footnotetext{
${ }^{60}$ Vid. Robert Alexy, “Zur Struktur der Rechtsprinzipien“, citado, pág. 52.

${ }^{61}$ Jan-Reinard Sieckmann, Regelmodelle und Prinzipienmodelle..., citado, pág. 86.
} 
intensidad de aplicación no puede ser modulada (como sucede con el que ordena respetar la vida), conviene revisar los sentidos en que puede interpretarse la noción de graduabilidad la cual, como ya se anticipó, es una de las propiedades asociadas a la definición de los principios como mandatos de optimización, normas que ordenan que algo se realice "en la mayor medida posible” ${ }^{62}$. Ahora bien, esta idea puede ser entendida en dos sentidos:

1) Como intensidad de la aplicación: predicable en el caso de aquellas normas que admiten un cumplimiento gradual o aproximativo (en una escala de 0 a 100\%), como sucede con la mayoría de los principios que prescriben la obtención de un estado de cosas (las directrices, en el lenguaje de Atienza y Ruiz Manero): garantizar un medio ambiente sano, el acceso a una vivienda digna, la protección de los consumidores, etc.

2) Como frecuencia de la aplicación. Tal es el sentido que adquiere la exigencia de cumplimiento "en la mayor medida posible” respecto de aquellos principios cuyo objeto no admite una realización aproximativa ("no matar", "no discriminar”), caso en el cual la exigencia que incorpora el mandato de optimización es una exigencia de cumplimiento "en el mayor número de ocasiones posibles”. En este sentido cabe entender la graduabilidad incorporada a la noción de mandato de optimización en el caso de aquellos principios que prescriben la realización de acciones $^{63}$.

De este modo, la caracterización de los principios como mandatos de optimización sería predicable tanto de las directrices (prescriben estados de cosas) como de los principios en sentido estricto (prescriben acciones).

\subsection{La configuración abierta de los principios}

Desde la concepción alexiana de los principios, la pregunta por las características presentes en la estructura condicional de la norma que determinan

\footnotetext{
62 Vid. supra 3.

${ }^{63}$ Vid. Alfonso García Figueroa, Principios y positivismo jurídico, citado, pág. 190, quien emplea una distinción similar, aunque establece una correlación entre la graduabilidad como intensidad y el cumplimiento de la norma (sistema del súbdito) y la graduabilidad como frecuencia y la aplicación de la norma (sistema del juez). A partir de esta distinción, parece inclinarse por una interpretación de la graduabilidad en el segundo sentido, al afirmar que "la graduabilidad del cumplimiento de la norma prescrita por el mandato de optimización no parece relevante” y además señalar que una aplicación gradual en el primer sentido "no parece ser el modo habitual de resolución de conflictos entre principios”. Por mi parte no acabo de entender la correlación que propone García Figueroa ni comparto la conclusión que de ella deriva, pues, en primer lugar, no se entiende por qué la graduabilidad, entendida como intensidad, deba entenderse sólo referida al sistema del súbdito, pues también podría ser vista como una norma, dirigida al juez, que prescribe una aplicación "mitte" del principio en cuestión, solución que, en contra de lo que sostiene el autor, sí resulta ser un modo habitual de resolución de conflictos entre principios.
} 
su tratamiento bien como una regla o bien como un principio ocupa un lugar secundario. Ello no quiere decir, sin embargo, que no ocupen ningún lugar. En efecto, la diferencia estructural que en el modelo de Atienza y Ruiz Manero se establece entre principios y reglas -formulación categórica de los primeros e hipotética de las segundas- guarda relación con la caracterización que propone Alexy de las reglas como normas que contienen determinaciones con relación a las posibilidades jurídicas y fácticas, y de los principios como normas que no establecen tal determinación ${ }^{64}$.

Desde el punto de vista de su formulación normativa, Alexy relaciona esta ausencia de determinación con la generalidad propia de los principios, los cuales "suelen ser relativamente generales porque no están referidos a las posibilidades del mundo real o normativo”65. Una norma será tanto más general cuanto menos específica sea la descripción de la conducta prescrita: así, la norma que ordena "no mentir” presenta un alto grado de generalidad, mientras que otra que prescribe "decir siempre la verdad al cónyuge en cuestiones monetarias” presenta un grado relativamente menor de generalidad $^{66}$. Pero a su vez, como se advierte en el ejemplo anterior, las normas más generales serían aquellas formuladas en términos categóricos, lo que sucede, según Atienza y Ruiz Manero, con los principios, cuya condición de aplicación no contiene otra cosa sino la propiedad de que haya una oportunidad de realizar la conducta prescrita en el consecuente ${ }^{67}$. Visto desde esta perspectiva, la formulación categórica de una norma, máxima expresión de su generalidad, sería una propiedad indicativa de la ausencia de determinación respecto a las posibilidades del mundo real y normativo, y con ello, de su carácter de principio. No obstante, en el planteamiento de Alexy el criterio de generalidad ocupa un lugar secundario porque no permite fundamentar una separación fuerte o cualitativa, sino sólo una distinción de grado, entre principios y reglas. Para este autor la menor o mayor generalidad del antecedente de una norma sería, por tanto, un criterio meramente indicativo, pero no constitutivo, de su carácter de regla o de principio ${ }^{68}$. Por su parte,

\footnotetext{
${ }^{64}$ Vid. Robert Alexy, Teoría de los Derechos Fundamentales, citado, pág. 99.

${ }^{65}$ Ibíd., pág. 103.

${ }^{66}$ Vid. Robert Alexy, “Zum Begriff des Rechtsprinzips”, citado, pág. 184, nota 37.

${ }^{67}$ Vid. Manuel Atienza y Juan Ruiz Manero, “Rules and Principles Revisited”, citado,

${ }^{68}$ Así, por ejemplo, cabría pensar en una norma como la formulada en el artículo 13 de la Constitución Colombiana, donde se establece que "no habrá pena de muerte”. Su formulación categórica daría lugar a calificarla como un principio, pues no establece una condición de aplicación distinta de la propiedad de que haya una oportunidad de realizar la conducta calificada como prohibida en el consecuente. Sin embargo, se trata de una norma que en el ordenamiento jurídico colombiano es interpretada como una regla, del mismo modo que en España se interpreta como regla la norma establecida en el artículo 15 de la Constitución que prohíbe imponer
} pág. 150. 
en cuanto a la formulación cerrada o abierta del consecuente, que en el modelo de Atienza y Ruiz Manero resulta un criterio decisivo para explicar la aplicación "todo o nada” de los principios en sentido estricto y cualidad de optimizables de las directrices, ya se ha visto como, de acuerdo a la concepción de Alexy, tal diferencia resulta del todo irrelevante ${ }^{69}$.

En todo caso, ha de admitirse que la formulación lingüística de las disposiciones normativas, a partir de las cuales es posible una mayor determinación de la condición de aplicación y consecuencia jurídica de las normas que en ellas se expresan, contribuye en alguna medida a la interpretación de dichas normas como principios o reglas. Así, por ejemplo, el hecho de que la Constitución Española no simplemente haya establecido en su artículo 15 que "todos tienen derecho a la vida”, sino que además haya proscrito la pena de muerte, sin duda ha servido para atrincherar este derecho (al menos en tiempo de paz) frente al riesgo de que sea interpretado como un derecho garantizado sólo "en la mayor medida posible” y a la postre derrotado cuando se consideren de mayor peso las razones de quienes abogan por implantar la pena de muerte. También ha contribuido a garantizar el derecho a la educación, y a que haya corrido mejor suerte que el derecho a la vivienda, el que la Constitución haya dispuesto que "la enseñanza básica será obligatoria y gratuita” (y asegurado su cumplimiento mediante el recurso de amparo). Sin embargo, las mismas cautelas no han impedido que el derecho al trabajo remunerado de los reclusos previsto en el artículo 25.2 se interprete como un derecho de aplicación progresiva "en la medida de lo posible”, pese a que su enunciado viene formulado al menos con la misma precisión que el de la norma que obliga a dispensar educación gratuita a los menores: ¿cuestión de formulación lingüística o de prioridades sociales?

Así pues, si la interpretación de una norma como portadora de un "deber ser real”, esto es, como una regla, o de un "deber ser ideal”, como un principio, parece ser independiente tanto de la configuración abierta de su consecuente, del carácter gradual de la conducta prescrita o de su formulación lingüística, ¿a qué responde entonces este peculiar modo de validez de los principios?

pena de muerte en tiempo de paz. Sin embargo, desde el criterio que sitúa en la generalidad el criterio de distinción entre reglas y principios, al igual que desde la distinción estructural que proponen Atienza y Ruiz Manero, sólo esta última norma sería una regla, mientras la primera sería un principio en sentido estricto. Este ejemplo corrobora la tesis que pretendo sostener, según la cual la interpretación de una norma como un principio (derrotable) o una regla (inderrotable) depende, en defínitiva, de las convenciones existentes en la sociedad en torno a la mayor resistencia que se concede a determinados contenidos normativos.

${ }^{69}$ Vid. supra 4.2.2.1. 


\subsection{La idea de mandato de optimización como convención interpretativa}

Un intento de responder a esta cuestión puede partir de una propuesta de reconstrucción teórica del derecho como fenómeno convencional, desarrollada por Bayón, según la cual toda práctica jurídica compleja incorpora convenciones interpretativas, definidas como "convenciones (específicas de dicha práctica) de segundo nivel respecto a las convenciones semánticas en virtud de las cuales tienen significado ordinario los enunciados formulados en ese lenguaje natural"70. La convención interpretativa más simple sería, explica este autor, la regla del significado literal. Pero sucede que las convenciones interpretativas imperantes en la práctica jurídica no suelen conformarse con dicha regla e, incluso, pueden requerir desviaciones del significado literal de distintos tipos. Cuando ello ocurre, la identificación del contenido del derecho requiere tomar en cuenta las convenciones interpretativas existentes ${ }^{71}$.

Creo que el concepto de convención interpretativa es fecundo para explicar el concepto alexiano de mandato de optimización. De acuerdo a él, la concepción de los principios como mandatos de optimización respondería a una convención interpretativa que podría articularse como un acuerdo según el cual, cierto tipo de decisiones jurídicas, los así llamados "casos difíciles", requieren que las normas que suministran las razones para decidir sean interpretadas no como portadoras de un "deber ser definitivo o real", esto es, como reglas, sino como portadoras de un "deber ser ideal o prima facie”, es decir, como principios. Mientras la primera interpretación llevaría a entender que las normas relevantes en el caso imponen deberes definitivos, que establecen una medida de cumplimiento determinada y que, en caso de conflicto, éste ha de saldarse con la declaración de invalidez o la excepción permanente de una de ellas, su interpretación como principios permite derivar de ellas sólo deberes prima facie, que admiten un cumplimiento gradual (sea en términos de intensidad o de frecuencia de aplicación), y resolver sus conflictos mediante la determinación de lo que dichas normas exigen en cada caso de acuerdo a las posibilidades tanto fácticas (a través de los juicios de idoneidad y necesidad que integran la máxima de proporcionalidad

\footnotetext{
${ }^{70}$ Juan Carlos Bayón, “Derecho, convencionalismo y controversia”, citado, pág. 63.

${ }^{71}$ Ibíd., pág. 63. En un sentido similar, señala Guastini que una teoría de la interpretación jurídica consiste, más que en una teoría del significado de los enunciados conforme al lenguaje natural, en una reconstrucción conceptual de la práctica de los operadores jurídicos. Vid. Riccardo Guastini, "Due esercisi di non-cognoscitivismo”, Analisi e Diritto, Torino, Giappichelli, 1999, págs. 277-280, aquí pág. 279.
} 
en sentido amplio) como jurídicas (a través de la ponderación o juicio de proporcionalidad en sentido estricto $)^{72}$.

Pero la calificación de una norma como principio o como regla no puede hacerse a partir de la interpretación aislada y abstracta de la disposición que la estatuye, sino sólo una vez puesta en relación con las circunstancias del caso a decidir y con las demás normas que resulten relevantes para el mismo pues, como se ha señalado con razón, "el hecho de que una norma contenga ya todas las determinaciones en relación con los principios o las reglas que jueguen en su contra, no puede constatarse sino en concreto, es decir, desde una perspectiva que tome en consideración las circunstancias particulares en que la norma debe ser aplicada"73. De este modo, en el juicio de constitucionalidad de las leyes que intervienen en derechos fundamentales, la interpretación de una norma iusfundamental como regla o principio sólo puede hacerse una vez considerada la relación que se plantea entre la constitución y la ley objeto de control a fin de determinar cuál es el problema jurídico a decidir. Si este problema puede ser considerado como un caso fácil, la norma iusfundamental será entonces tratada como una regla, y en este caso la contradicción que eventualmente se constate entre su contenido y el de la ley enjuiciada se saldará con la aplicación del criterio jerárquico de resolución de antinomias; si, por el contrario, se trata de un caso difícil, la norma iusfundamental será tratada como un principio que se opone a las demás razones (de principio) que avalan la constitucionalidad de la ley enjuiciada y cuya colisión debe resolverse a través del principio de proporcionalidad.

Si esta interpretación es correcta, la posición de Alexy, quien expresamente defiende una tesis fuerte de la separación entre principios y reglas, termina por aproximarse bastante a la de aquellos autores que sostienen una tesis débil de la separación, no a partir del criterio de la generalidad sino sobre la base de entender que la distinción entre ambos tipos de normas es, en definitiva, "una variable dependiente de las diversidades en la interpretación y aplicación, en la argumentación y en la solución de los conflictos"74. De

${ }^{72}$ La convención que sugiere entender los principios como mandatos de optimización no sería sino otro modo de nombrar a la convención interpretativa que lleva a entender que algunas normas sólo tienen validez prima facie, a la cual se refiere Bayón en el trabajo antes citado como "una convención que se autoanula en sentido débil”. Juan Carlos Bayón, "Derecho, convencionalismo y controversia”, citado, pág. 68 y 88 (nota 50).

${ }^{73}$ Carlos Bernal, El principio de proporcionalidad..., citado, pág. 588.

${ }^{74}$ Se suelen identificar dos posiciones básicas sobre la relación entre principios y reglas: por un lado están quienes sostienen que entre ambas existe una separación fuerte (strenge Trennungsthese) y, por otro, quienes afirman que sólo es posible establecer una separación débil entre unos y otras (schwache Trennungsthese): La tesis fuerte de la separación, en la que se inscriben planteamientos como los de Dworkin, Alexy o Atienza y Ruiz Manero, afirma que entre dichas normas existe una distinción cualitativa y exhaustiva, con lo cual "toda norma es o 
hecho, en un trabajo reciente Alexy se inclina a considerar que la distinción entre reglas y principios "es una cuestión de interpretación", en la que "como siempre ocurre con la interpretación, no hay criterios que permitan en todos los casos una respuesta fácil y clara" ${ }^{\text {", }}$, pese a lo cual este autor sostiene que el hecho de admitir que la diferencia es un asunto de interpretación, "no plantea ninguna objeción contra el carácter de principio como una propiedad de la estructura de la norma" ${ }^{\text {". }}$. En efecto, ambas afirmaciones resultan compatibles cuando, a partir del concepto semántico de norma que sostiene este autor, se entiende que la norma, en cuanto atribución de significado a una disposición, es precisamente el resultado de la interpretación, y que sólo tras esta última se le atribuye a la norma su estructura deóntica, esto es, su carácter de deber ser ideal (principio) o de un deber ser definitivo o real (regla). De este modo, la posición de Alexy en torno a la separación entre principios y reglas no parece guardar diferencias significativas con la de aquellos autores que, como Letizia Gianformaggio, sostienen que "la diferencia entre reglas y principios emerge exclusivamente en el momento de la interpretación-aplicación", de tal suerte que sostener que "una cierta disposición contiene una regla en lugar de un principio o viceversa, no significa otra cosa que sugerir prácticas interpretativo-aplicativas de un tipo en lugar de otro" $"$.

bien una regla o un principio”. Como explica Paolo Comanducci, quienes sostienen este punto de vista entienden que "la diversidad en la tipología de las normas entre principios y reglas es condición necesaria y suficiente de la diversidad en la interpretación y aplicación de principios y reglas, de la diversidad de argumentación a partir de principios o a partir de reglas, y de la diversidad de solución de conflictos entre principios y entre reglas" ("Principios jurídicos e indeterminación del derecho”, Doxa, 21-II, 1998, págs. 89-104, aquí pág. 93). Por el contrario, la tesis débil de la separación conoce dos versiones: la primera afirma que aunque entre reglas y principios cabe establecer una distinción relevante, tal diferencia es sólo de grado y fundan tal distinción sobre el criterio de generalidad; la segunda versión de la tesis débil es sostenida por quienes consideran que "la diferencia en la tipología de las normas entre reglas y principios es una variable dependiente de las diversidades en la interpretación y aplicación, en la argumentación y en la solución de los conflictos” (Ibíd., pág. 93 y s). De acuerdo a esta segunda variante de la tesis débil, por la que se decanta el profesor italiano, la calificación de una norma como principio no depende de alguna cualidad de tipo ontológico presente en la norma como tal, sino más bien de una configuración que se realiza en función del modo en que ésta es interpretada o aplicada, de la manera en que se argumenta a partir de ella o del modo de resolver sus eventuales conflictos; configuración que, si bien descansa en una elección valorativa del intérprete, suele justificarse sobre la base de ciertas características que presenta la norma en cuestión.

${ }^{75}$ Robert Alexy, “Zur Struktur der Rechtsprinzipien”, citado, pág. 38.

${ }^{76}$ Ibíd., pág. 38.

${ }^{77}$ Letizia Gianformaggio, "L'interpretazione della Costituzione tra applicazione di regole ed argomentazione basata su principi”, Rivista Internazionale di Filosofia del Diritto, 1985/1, págs. 65-103, aquí pág. 72. Próximos a esta variante de la tesis débil de la separación entre reglas y principios son también los planteamientos de Luis Prieto, Sobre principios y normas. Problemas del razonamiento jurídico, Madrid, Centro de Estudios Constitucionales, 1992, 
Dando un paso más en esta comparación se advierte que la relación conceptual entre principios y máxima de proporcionalidad presentada por el autor germano como punto de partida de su construcción teórica, en el fondo se sustenta en la asunción de una vinculación necesaria entre el concepto de principio y una cierta configuración de los conflictos normativos, en la línea sugerida por los partidarios de la tesis débil de la separación en el sentido antes indicado. En este orden de ideas hablamos de principios sólo cuando nos hallamos en presencia de normas que: 1) no operan en el razonamiento de modo aislado, en el sentido de que por sí solas no ofrecen fundamento a una decisión jurídica, sino que siempre lo hacen en conjunción con otras normas (otros principios) que orientan la decisión en sentido contrario, de tal suerte que el concepto de principio aparece invariablemente ligado a la idea de conflicto normativo ${ }^{78} ; 2$ ) cuando para resolver dicho conflicto no se consideran de recibo los mecanismos tradicionales de resolución de antinomias, basados en la anulación o excepción permanente de una de las normas en conflicto, y en su lugar se adopta el esquema de argumentación que suministra el principio de proporcionalidad. Así pues, cuando se verifican ambas condiciones llamamos principios a las normas involucradas en el razonamiento y las interpretamos como portadoras de deberes prima facie en lugar de como portadoras de deberes definitivos. La vinculación conceptual entre principios y máxima de proporcionalidad a la que se refiere Alexy existe, pues, debido a que llamamos principios sólo a las normas que, ante un determinado caso, no admiten una satisfacción plena de su objeto porque

pág. 55, quien sostiene que “muy probablemente, en el lenguaje jurídico, los principios no son un determinado tipo de normas [...], sino cualquier norma en cuanto adopta una determinada posición o papel en el razonamiento o argumentación jurídica”; Juan Ramón de Páramo, "Razonamiento jurídico e interpretación constitucional”, Revista Española de Derecho Constitucional, 22, 1988, págs. 89-119, aquí pág. 108, para quien "la conocida distinción entre reglas y principios se puede reducir a diferentes prácticas interpretativas-aplicativas que, a su vez, proponen una teoría del razonamiento jurídico como tipo especial del práctico”; Alfonso García, Principios y positivismo jurídico, citado, pág. 154, cuando, tras coincidir con la posición de estos autores, concluye que "el lugar idóneo para el estudio de los principios no se halla en el propio sistema de fuentes, sino en el momento de la aplicación del derecho”.

${ }^{78}$ En tal sentido señala Letizia Gianformaggio que "aplicar un principio es distinto de aplicar una regla en cuanto la aplicación del principio comporta también siempre la aplicación de otro principio que se asume con aquél concurrente y relevante en la situación específica, de modo tal que la conclusión de la argumentación se deriva de las consideraciones en las cuales son tenidas en cuenta, en la situación específica, ambos principios”, con lo cual, “en rigor, si uno de los principios concurrentes viene 'inaplicado', entonces no puede decir de ninguna manera que venga aplicado el otro principio: en realidad viene aplicada una regla”. "L’interpretazione della Costituzione...”, citado, pág. 91. 
entran en colisión con otras normas, y cuando para resolver tal colisión aplicamos la máxima de proporcionalidad ${ }^{79}$.

Por otra parte, la adopción de esta convención interpretativa en relación con ciertas normas se explicaría, en primer lugar, como una respuesta a la necesidad, constitutiva del modelo de organización política representado en el estado constitucional, de posibilitar la coexistencia en el ordenamiento de un orden de valores plural y, por ello, tendencialmente conflictivo, como el que incorporan los textos constitucionales en la actualidad. En segundo lugar, es el resultado del doble entendimiento de la constitución como un orden fundamental y a la vez como un marco, comprensión que parece necesaria para conciliar, por un lado, el papel que desempeña la constitución como límite al poder, y, por otro, la libertad de configuración del legislador democrático. En suma, la interpretación de los contenidos constitucionales como "mandatos de optimización" pone de manifiesto y a la vez se propone como un intento de resolver el dilema que está en la base del constitucionalismo: la tensión entre democracia y derechos fundamentales ${ }^{80}$.

Tal convención interpretativa es igualmente aplicable a los derechos fundamentales, cuyo entendimiento en términos de mandatos de optimización no sólo ha de ser visto como una amenaza a su fuerza normativa, por la posibilidad de que éstos sean ponderados con y, eventualmente derrotados por, principios que expresen bienes colectivos u otro tipo de razones de utilidad. La concepción de los derechos fundamentales como mandatos de optimización también reporta ventajas desde un punto de vista liberal, pues la interpretación de los derechos fundamentales como normas que reclaman el mayor grado de satisfacción posible atendiendo a las circunstancias jurídicas y fácticas de cada caso, permite atribuirles un ámbito inicial de protección mucho más amplio del que supone su aplicación en términos todo/nada. En efecto, para que en una reconstrucción como la que proponen Atienza y Ruiz Manero los derechos fundamentales (principios en sentido estricto) siempre se impongan sobre los bienes colectivos y otras razones de utilidad (las directrices), es preciso asumir una concepción estrecha acerca del contenido de los derechos que de antemano elimine de los mismos cualquier

\footnotetext{
${ }^{79}$ En esta dirección sostiene Luis Prieto que lo que se pone de manifiesto cuando se establece un vínculo entre ponderación y principios "no es que un principio se caracteriza por operar en el marco de un conflicto según la ley de la ponderación, sino que, al contrario, cuando hacemos uso de esa técnica de solución de conflictos debemos decir que aplicamos principios". "Diez argumentos a propósito de los principios", en Ley, principios, derechos, Madrid, Dykinson, 1998, págs. 47-68, aquí pág. 61.

${ }^{80}$ Sobre la relación de la teoría de los principios con este doble entendimiento de la constitución vid. Robert Alexy, "Epílogo a la Teoría de los Derechos Fundamentales”, citado, págs. 17 y ss.
} 
contenido que pueda ser razonablemente limitado en virtud de estos últimos. Así, por citar un conocido ejemplo extraído de la jurisprudencia constitucional alemana, posiciones tales como pintar en los cruces de calles o alimentar palomas no pertenecerían al mundo de los derechos fundamentales, pues de otro modo no sería posible su limitación en aras de garantizar la fluidez del tráfico o la protección del patrimonio arquitectónico de las ciudades.

Se trata de dos formas distintas de concebir el contenido de los derechos y la relación con sus límites: la primera, adscribe a ellos un amplísimo ámbito inicial de protección prima facie sobre el cual luego es posible introducir restricciones (derivadas de otros derechos o de otro tipo de principios); la segunda excluye de antemano los modos de ejercicio del derecho que pudiesen entrar en conflicto con intereses colectivos, para luego atrincherar el contenido restante de los derechos frente a restricciones basadas en razones de utilidad ${ }^{81}$. Posiblemente a través de las dos vías se llegue al mismo resultado en los casos fáciles, allí donde fácilmente se admitiría la legitimidad de una restricción. La diferencia importante se advierte en los casos difíciles, cuando no es claro si una cierta posición debe o no integrarse al contenido definitivo de los derechos: así, en el caso de la alimentadora de palomas, la concepción de los derechos como mandatos de optimización, al integrar la posición sobre la que se debate al ámbito de protección prima facie del libre desarrollo de la personalidad, impone a quien pretende restringir tal derecho la carga de justificar su limitación. En cambio, de acuerdo a la segunda concepción, dado que tal posición no forma parte del contenido protegido por los derechos fundamentales, no se impondría dicha carga de justificación: ¿cuál sería la razón para exigir tal justificación, si la restricción recae sobre un espacio de libertad "natural” que no vincula a los poderes públicos? ${ }^{82}$ En esta diferencia se sitúa la repercusión práctica de una y otra reconstrucción y es ella la que, a mi modo de ver, confiere mayores ventajas a la concepción de los principios como mandatos de optimización. Sin embargo, tal reconstrucción no está exenta de problemas. De uno de ellos me ocupo a continuación.

${ }^{81}$ Distinción que coincide con la que se propone entre una teoría externa de los derechos fundamentales (concebidos como mandatos de optimización) y las llamadas "teorías internas". $\mathrm{Al}$ respecto vid. Carlos Bernal, El principio de proporcionalidad..., citado, págs. 442 y ss.

${ }^{82}$ Sobre esto ha llamado la atención Luis Prieto Sanchís, "La limitación de los derechos fundamentales y la norma de clausura del sistema de libertades”, en Justicia constitucional y derechos fundamentales, Madrid, Trotta, 2003, págs. 217-260. 


\section{In dubio: ¿Pro derechos o pro legislatore?}

La teoría de los principios de Alexy sin duda representa uno de los más importantes esfuerzos por ofrecer parámetros de racionalidad que orienten la argumentación jurídica y, en particular, la que tiene lugar en sede de control de constitucionalidad de las leyes. Sin embargo, ella sigue sin ofrecer una respuesta satisfactoria a la principal objeción que, desde un punto de vista sustancial, se ha formulado contra la concepción de los derechos fundamentales como principios a optimizar, y es que la misma puede conducir a una relativización del contenido de los derechos fundamentales que en algunos casos permitiría incluso su negación definitiva, si se logra argumentar satisfactoriamente que ello es necesario en razón de las circunstancias jurídicas y fácticas. En el modelo teórico de Alexy tal desplazamiento puede tener lugar no sólo porque así lo exija otro derecho fundamental (cuyo peso se juzgue mayor en el caso concreto), sino también porque ello sea necesario para satisfacer un bien colectivo. Concebidos pues como mandatos de optimización, los derechos fundamentales garantizarían "demasiado poco" ${ }^{83}$.

Como hemos visto, la respuesta de Alexy a este virtual desamparo al que se exponen los derechos fundamentales concebidos como principios, consiste en afirmar la prevalencia prima facie de los derechos individuales sobre los bienes colectivos, expresada en una carga de la argumentación a favor de los primeros ${ }^{84}$. Ella corresponde, para el caso de los derechos de libertad, a la fórmula "in dubio pro libertate" ${ }^{85}$, pero que extendida a los derechos de prestación y de igualdad podría expresarse en un genérico "in dubio pro derechos", según el cual, planteada una colisión entre un derecho individual y un bien colectivo, toda duda o empate entre razones igualmente buenas se resuelve a favor del derecho individual.

No obstante, al tiempo que se afirma lo anterior se sostiene, por otro lado, la prevalencia de las reglas sobre los principios, argumentando que aquellas tienen un carácter prima facie diferente y esencialmente fuerte respecto al que poseen los principios. La razón de esta mayor fuerza de las reglas radica en que éstas, además de venir respaldadas por principios sustanciales, cuentan con el apoyo de principios formales que ordenan seguir las determinaciones impuestas por una autoridad legítima. En sus trabajos más recientes, este planteamiento ha desembocado en el reconocimiento de

\footnotetext{
${ }^{83}$ No obstante, Böckenförde ha formulado la objeción contraria, según la cual, concebidos como principios, los derechos fundamentales garantizarían “demasiado”. A ambas objeciones se refiere Alexy en su "Epílogo a la Teoría de los Derechos Fundamentales”, citado, págs. 14 y s.

${ }^{84}$ Vid. supra 4.2.2.2.

${ }^{85}$ Vid. Robert Alexy, “Derechos individuales y bienes colectivos”, citado, pág. 207.
} 
un margen estructural para la ponderación a favor del legislador, bajo el entendido de que "si las razones para la intervención son tan fuertes como las razones que juegan en su contra, la intervención no es desproporcionada" ${ }^{\text {, }}$, lo que se traduce en una suerte de "in dubio pro legislatore".

La confluencia entre una y otra regla de decisión se produce en todos los casos, por cierto no poco frecuentes, de intervenciones legislativas en derechos fundamentales que no están justificadas por la protección de otro derecho fundamental sino de un bien colectivo, evento en el cual emerge una antinomia entre dos criterios de precedencia prima facie de signo contrario: de existir dudas o empate entre argumentos igualmente buenos en pro y en contra de la limitación del derecho, el “in dubio pro derechos" impone decidir a favor del derecho fundamental y, en consecuencia, considerar injustificada su limitación, mientras que el “in dubio pro legislatore” lleva a considerar justificada la determinación legislativa de restringir el derecho individual en aras de un bien colectivo ${ }^{87}$. En este caso, la contradicción entre ambos criterios de prevalencia conduce a su anulación recíproca y, en consecuencia, a la situación de paridad o de "empate” entre derechos fundamentales y bienes colectivos. Así pues, la prioridad prima facie de los derechos individuales, dirigida a preservar su carácter de "triunfo" frente a otro tipo de intereses colectivos, está destinada a ser neutralizada por el reconocimiento paralelo de un margen decisorio a favor del legislador, cuya existencia constituye, a juicio de Alexy, "el imprescindible tributo que los ideales iusfundamentales tienen que pagar a cambio del triunfo, nunca suficientemente apreciado, de su institucionalización en el mundo, tal como es”88.

\footnotetext{
${ }^{86}$ Robert Alexy, “Epílogo...”, citado, pág. 45. En el mismo sentido se pronuncia en "Entrevista a Robert Alexy”, trad. M. Atienza, Doxa, 24, 2001, págs. 671-687, aquí pág. 678.

${ }^{87}$ Contradicción que Carlos Bernal ha destacado como uno de los límites de racionalidad de la ponderación, “Estructura y límites de la ponderación”, Doxa, 26, 2003, págs. 225-238, aquí págs. 230 y ss, 237.

${ }^{88}$ Robert Alexy, “Epílogo a la Teoría de los Derechos Fundamentales”, citado, pág. 64. En sus últimos trabajos este autor ha intentado resolver esta contradicción mediante la introducción de una variable en la ponderación que tiene lugar en el juicio de proporcionalidad en sentido estricto. A través de esta variable, que denomina peso abstracto, es posible atribuir a los derechos fundamentales una mayor fuerza justificatoria respecto de los bienes colectivos. No se trataría de una prioridad absoluta, por cuanto el peso definitivo de cada uno de los principios que intervienen en la ponderación dependería de otras variables, además del peso abstracto, como son la intensidad de la afectación y la certeza de las premisas empíricas referidas a dicha afectación, pero en todo caso permitiría reforzar la resistencia de las "razones de corrección" expresadas en los derechos fundamentales, frente a las razones de fin expresadas en los bienes colectivos. Al respecto remito a lo afirmado por el autor en el coloquio posterior a su conferencia "Balancing, Constitucional Review and Representation", pronunciada en la Universidad de Alicante el 24 de mayo de 2004.
} 


\section{Conclusiones}

7.1. El entendimiento de una norma como un mandato de optimización no depende de modo decisivo de la estructura abierta de su antecedente y su consecuente, ni de su consideración en términos de razones de utilidad, sino ante todo del modo de validez que se le atribuye en virtud de una convención interpretativa empleada por los operadores jurídicos cuando el caso a decidir se cataloga como "difícil”, por existir una colisión entre estándares normativos que orientan soluciones contrapuestas y se considera que la antinomia en cuestión no admite ser resuelta a partir de los criterios tradicionales de resolución de antinomias.

7.2. Tal convención interpretativa es igualmente aplicable a los derechos fundamentales, cuyo entendimiento en términos de mandatos de optimización reporta ventajas desde un punto de vista liberal, pues permite atribuirles un ámbito inicial de protección mucho más amplio del que supone su aplicación en términos todo/nada. Ámbito que si bien admite restricciones, impone la carga de justificación a quien pretenda realizarlas. Desde esta perspectiva, resulta entonces posible mantener la aplicación de la máxima de proporcionalidad para resolver las colisiones en las que intervienen derechos fundamentales, entre ellas, las que tienen lugar cuando se controla la constitucionalidad de leyes penales.

7.3. Sin embargo, la concepción de los derechos fundamentales como mandatos de optimización, tal y como es desarrollada por Alexy, se enfrenta al riesgo de que sus contenidos garanticen “demasiado poco” y, con ello, a disminuir su potencial limitador del poder, en el que en definitiva, reside su valor, incluso cuando el poder que se pretende limitar cuente con el respaldo de las mayorías. Por ello es preciso refinar el desarrollo de esta estructura argumentativa a fin de integrar elementos que hagan valer la irrenunciable primacía del individuo y sus derechos frente a otro tipo de razones basadas en el interés del colectivo.

7.4. Pero más importante aún es cobrar conciencia de que la resistencia de los derechos no descansa, en definitiva, en las características estructurales de las normas que los acogen o en el tipo de razón para la acción que representen. Antes bien, el que sigan siendo "razones últimas", depende del consenso de los ciudadanos en torno a la importancia de preservar los derechos como "triunfos frente a la mayoría", el que a su vez influye en la conformación de las convenciones interpretativas imperantes en dicha sociedad en torno al alcance y resistencia de los derechos. El problema no radica pues en una suerte de perversidad intrínseca de la concepción de los derechos fundamentales como mandatos de optimización o en el empleo del principio de proporcionalidad como criterio para enjuiciar la constitucionalidad de las decisiones que los afecten, sino en la precaria resistencia normativa que en 
el momento actual tiende a reconocerse a las libertades del individuo cuando topan contra consideraciones de eficiencia punitiva, lucha antiterrorista y otros ropajes con los que suele vestirse la nuda razón de estado. Precariedad que se hace explícita en el elevado peso que en el debate público y en la argumentación constitucional adquieren estos últimos imperativos en contraste con el retórico reconocimiento de la fuerza normativa de los derechos. Precisamente el empleo de técnicas argumentativas como el principio de proporcionalidad hacen visibles y explícitas este tipo de consideraciones, y su vez posibilitan el control y la crítica de los fundamentos que acompañan tales valoraciones.

Entender pues que los derechos fundamentales pueden operar en el razonamiento como mandatos de optimización, y que ello no depende sino de una convención interpretativa en virtud de la cual fijamos el alcance que queremos dar a los derechos, permite darnos cuenta que su fuerza descansa, en definitiva, en la estima que los ciudadanos tienen de sus libertades, pues, como ha puesto de manifiesto lúcidamente Ferrajoli, “(l)a Constitución, y en general el Derecho, no (son) otra cosa que un conjunto de significados. Rigen, funcionan, mientras su sentido es socialmente compartido. De otro modo, desaparecen, junto a los valores que garantizan, sin necesidad de golpes de estado o cambios institucionales" ${ }^{89}$.

\footnotetext{
${ }^{89}$ Luigi Ferrajoli, "El estado constitucional de derecho hoy: el modelo y su divergencia con la realidad”, trad. P. Andrés Ibáñez, en Corrupción y Estado de Derecho. El papel de la jurisdicción. Madrid, Trotta, 1996, pág. 29.
} 
$\triangle \quad$ DOXA 27 (2004) 